\title{
ÉPOCA DE COLETA DE EXPLANTES E FITOREGULADORES NA MULTIPLICAÇÃO IN VITRO DE CITRONELA DE JAVA
}

\section{CUTTING TIME OF THE EXPLANTS AND PHYTOREGULATORS ABOUT THE PROPAGATION IN VITRO OF JAVA CITRONELLA}

\author{
Luciani Márcia SCHERER-SALVARO ${ }^{1}$ \\ Márcia de Moraes ECHER ${ }^{2}$ \\ Vandeir Francisco GUIMARÃES ${ }^{3}$ \\ Elisiane Inês DALL'OGLIO-CHAVES ${ }^{4}$ \\ Andréa Maria Teixeira FORTES ${ }^{5}$
}

\begin{abstract}
RESUMO
O objetivo deste trabalho foi avaliar o efeito das épocas de coleta e de fitoreguladores sobre a propagação in vitro da citronela de Java (Cymbopogon winterianus Jowitt). Os explantes foram coletados em cada uma das estações do ano e inoculados em meio de cultura MS acrescido de concentrações de AIB $\left(0,0 ; 0,1 ; 0,2\right.$ e $\left.0,3 \mathrm{mg} \mathrm{dm}^{-3}\right)$ e BAP $(0,0 ; 1,0 ; 2,0$ e 3,0 $\mathrm{mg} \mathrm{dm}^{-3}$ ) combinadas e isoladas entre si. O delineamento experimental foi inteiramente casualizado. Ao final de 30 dias foram avaliadas as variáveis: altura, número de brotações, formação de calo e oxidação. A maior taxa de brotação foi obtida a partir dos explantes coletados no verão (2,87 brotos por explante), sendo a concentração ideal $1,73 \mathrm{mg} \mathrm{dm}^{-3}$ de BAP ao meio de cultura, e ausência de oxidação nesta condição. A altura dos explantes somente apresentou resultados significativos com explantes obtidos no inverno. Para os materiais obtidos no outono, inverno e verão ocorreu formação de calo, sendo que nos de verão houve também um aumento no número de brotações por explante. A oxidação se deu de forma mais intensa nos explantes coletados na primavera.

Palavras-chave: Cymbopogon winterianus Jowitt; sazonalidade; micropropagação.
\end{abstract}

\begin{abstract}
The objective of this study was to evaluate the effect of the seasonally and phytoregulators about the propagation in vitro of Java citronella. The explants were collected in each season of the year and inoculated in MS medium in addition to concentrations of IBA $\left(0,0 ; 0,1 ; 0,2 \mathrm{e} 0,3 \mathrm{mg} \mathrm{dm}^{-3}\right)$ and BAP $\left(0,0 ; 1,0 ; 2,0\right.$ e $\left.3,0 \mathrm{mg} \mathrm{dm}^{-3}\right)$ combined and isolated among oneself. The present study was completely randomized design. At the end of 30 days the following parameters had been evaluated: height, number of shootings, formation of callus and oxidation. The higher multiplication was obtained in explants were collected during the summer (2.87 shootings) being ideal concentration $1.73 \mathrm{mg} \mathrm{dm}^{-3}$ of BAP in the medium culture and absence of oxidation in explants collected in this season. The height only presented significant results in explants were collected during the winter. It had formation of callus either in explants were collected during the autumn or in the winter and in the summer. But in the explants were collected during the summer it had a concomitant increase in the number of shootings. The oxidation was higher in the explants were collected during the spring.
\end{abstract}

Key-words: Cymbopogon winterianus Jowitt; seasons; micropropagation.

\footnotetext{
${ }^{1}$ Pós-graduanda em Ciências Biológicas (Botânica), Universidade Estadual Paulista "Júlio de Mesquita Filho" (UNESP), Instituto de Biociências, Campus de Botucatu-SP. Botucatu-SP, Brasil. E-mail: lumascherer@hotmail.com.

${ }^{2}$ Professor Adjunto do Centro de Ciências Agrárias, Universidade Estadual do Oeste do Paraná (UNIOESTE), Marechal Cândido Rondon-PR, Brasil. E-mail: mmecher@pq.cnpq.br.

${ }^{3}$ Prof. Adjunto do Centro de Ciências Agrárias da Universidade Estadual do Oeste do Paraná, Rua Pernambuco, 1777, Marechal Cândido Rondon-PR, Brasil, Cx. Postal 91 - CEP 85960-000. Autor para correspondência. E-mail: vandeirfg@yahoo.com.br.

${ }^{4}$ Msc., Docente da Pontifícia Universidade Católica (PUC-PR), Campus de Toledo. Toledo-PR, Brasil. E-mail: elisiane.oglio@pucpr.br.

${ }^{5}$ Professor Adjunto do Curso de Ciências Biológicas da Universidade Estadual do Oeste do Paraná, Campus de Cascavel. Cascavel-PR, Brasil. E-mail: amtfortes@unioeste.br.
} 
SCHERER-SALVARO, L.M. et al. Época de coleta de explantes...

\section{INTRODUÇÃO}

A citronela de Java (Cymbopogon winterianus Jowitt) é uma gramínea aromática de grande valor econômico devido ao seu óleo essencial e também a sua propriedade repelente contra insetos. Normalmente a citronela floresce na Região Sul do Brasil durante os meses da primavera e início do verão, porém não dá sementes viáveis (Castro \& Chemale, 1995). Deste modo a propagação da citronela é realizada pela divisão de touceiras (Blank et al., 2004), sendo que este método apresenta a desvantagem da contaminação das mudas, que se dá principalmente por fusariose.

Uma alternativa que vem se tornando eficiente e viável é a utilização da técnica de micropropagação, podendo ser empregada não só na produção de mudas sadias, mas também para a produção de novos genótipos com resistência à fusariose (Araújo et al., 2008). Além disso, esta técnica já tem apresentado resultados excelentes no que se refere à propagação de espécies medicinais, aromáticas, condimentares, ornamentais e inclusive florestais.

De modo geral, o crescimento e desenvolvimento das plantas é fortemente influenciado por condições climáticas como pluviosidade, temperatura e fotoperíodo. Ao elaborar um protocolo de multiplicação e regeneração de citronela in vitro, Zigiotto (2004) percebeu que a espécie apresenta dificuldades de propagação em alguns períodos do ano.

Deste modo, o objetivo deste trabalho foi avaliar o efeito das épocas de coleta dos explantes e de fitoreguladores (AIB-ácido indolilbutírico e BAP-benzilaminopurina), em diferentes concentrações sobre a micropropagação da citronela de Java (Cymbopogon winterianus Jowitt).

\section{MATERIAL E MÉTODOS}

O trabalho foi realizado no Laboratório de Cultura de Tecidos da UNIOESTE- Campus de Marechal Cândido Rondon, PR. Foram conduzidos 4 experimentos durante $o$ ano de 2005, um em cada estação do ano, sendo todos realizados geralmente na metade de cada estação (maio/2005, agosto/2005, outubro/2005, janeiro/2006). O material vegetal utilizado foi obtido na Fazenda São Roque, situada na zona rural do município de Marechal Cândido Rondon-PR.

O explante utilizado foi a gema apical com aproximadamente $1 \mathrm{~cm}$ de comprimento e a assepsia dos explantes foi realizada baseando-se na metodologia adotada por Zigiotto (2004) para a citronela de Java, onde, os explantes já extraídos foram colocados em solução de água destilada com algumas gotas de Tween 80 . Em seguida procedeuse a imersão dos explantes em hipoclorito de sódio $2,5 \%$ durante 10 min e neste momento os explantes foram levados para a capela de fluxo laminar, onde se procedeu o restante da assepsia. Os explantes foram imersos em álcool $70 \%$, durante $5 \mathrm{~min}$ e posteriormente em hipoclorito de sódio $2,5 \%$, durante 30 min e por fim houve a imersão em álcool $70 \%$, durante $3 \mathrm{~min}$. Após estes procedimentos realizou-se a tríplice lavagem em água destilada e autoclavada. Terminado o processo de assepsia dentro da câmara de fluxo laminar, os explantes foram mantidos imersos em água destilada e autoclavada enquanto a inoculação foi realizada.

O meio de cultura utilizado foi o MS (Murashige \& Skoog, 1962), acrescido de $30 \mathrm{~g} \mathrm{dm}^{-3}$ de sacarose, $7 \mathrm{~g} \mathrm{dm}^{-3}$ de ágar, sendo o $\mathrm{pH}$ do meio ajustado para 5,8 antes da autoclavagem a $120^{\circ} \mathrm{C}$ durante $20 \mathrm{~min}$. Ao meio de cultura foram adicionadas as diferentes concentração de AIB (ácido indolilbutírico) e BAP (benzilaminopurina) combinadas ou não, conforme a Tabela 1.

TABELA 1 - Tratamentos utilizados para regeneração de gemas apicais de citronela de Java (Cymbopogon winterianus Jowitt) em meio MS (Murashige \& Skoog, 1962) com diferentes combinações de AlB (ácido indolilbutírico) e BAP (benzilaminopurina).

\begin{tabular}{|c|c|c|c|}
\hline Tratamentos & Concentrações $\left(\mathrm{mg} \mathrm{dm}^{-3}\right)$ & Tratamentos & Concentrações $\left(\mathrm{mg} \mathrm{dm}^{-3}\right)$ \\
\hline $\mathrm{T1}$ & $0,0 \mathrm{AlB} \times 0,0 \mathrm{BAP}$ & T9 & $0,2 \mathrm{AIB} \times 0,0 \mathrm{BAP}$ \\
\hline T2 & 0,0 AIB X 1,0 BAP & T10 & $0,2 \mathrm{AIB} X 1,0 \mathrm{BAP}$ \\
\hline T3 & 0,0 AIB X 2,0 BAP & T11 & $0,2 \mathrm{AIB} \times 2,0 \mathrm{BAP}$ \\
\hline T4 & 0,0 AIB $\times 3,0$ BAP & T12 & 0,2 AIB X 3,0 BAP \\
\hline T5 & 0,1 AIB $\times 0,0$ BAP & $\mathrm{T} 13$ & 0,3 AIB $\times 0,0$ BAP \\
\hline T6 & $0,1 \mathrm{AIB} \times 1,0 \mathrm{BAP}$ & T14 & $0,3 \mathrm{AIB} X 1,0 \mathrm{BAP}$ \\
\hline $\mathrm{T7}$ & $0,1 \mathrm{AlB} \times 2,0 \mathrm{BAP}$ & T15 & $0,3 \mathrm{AlB} \times 2,0 \mathrm{BAP}$ \\
\hline T8 & 0,1 AIB $\times 3,0$ BAP & T16 & 0,3 AIB $\times 3,0$ BAP \\
\hline
\end{tabular}

A inoculação foi realizada em câmara de fluxo laminar, previamente esterilizada com álcool $70 \%$. Os frascos utilizados neste estudo eram de vidro, com tampa plástica. Em cada frasco foi despejado $30 \mathrm{~cm}^{3}$ de meio de cultura antes da autoclavagem. No momento da inoculação, cada 
frasco recebeu um explante. Posteriormente, os frascos foram levados para a sala de crescimento com temperatura de $26^{\circ} \mathrm{C}$, onde permaneceram no escuro total durante 15 dias, a fim de se evitar a oxidação e estresse dos explantes, pois nas plantas, estes não estavam expostos à luz. Após o período de 15 dias no escuro, os explantes foram expostos à luz (fotoperíodo $16 \mathrm{~h}$ claro e $8 \mathrm{~h}$ escuro), dando início a fase de multiplicação, que seguiu por mais 15 dias na mesma temperatura, onde ao final foi realizada a avaliação dos explantes, com 30 dias após a inoculação (DAI).

Foram avaliadas as variáveis: altura média dos explantes, número de brotos por explante, porcentagem de oxidação e presença de calo. O delineamento experimental utilizado foi inteiramente casualizado em esquema fatorial $(4 \times 4)$ sendo 4 concentrações de AIB e 4 concentrações de BAP com 8 repetições por tratamento, sendo um explante por tratamento, totalizando 16 tratamentos. Os dados obtidos foram tabulados e submetidos à análise de variância e as médias comparadas pelo teste de Tukey a $5 \%$ de probabilidade. Utilizou-se também análise de regressão para as variáveis avaliadas em função das concentrações de fitoreguladores adicionadas ao meio de cultura.

\section{RESULTADOS E DISCUSSÃO}

\section{Altura dos explantes}

Em relação à variável altura média dos explantes, somente houve efeito significativo para os explantes coletados no inverno em função das concentrações de AIB adicionadas ao meio de cultura. (Figura 1). Nas outras épocas de coleta de explantes não houve efeito significativo para ambos os fitoreguladores utilizados.

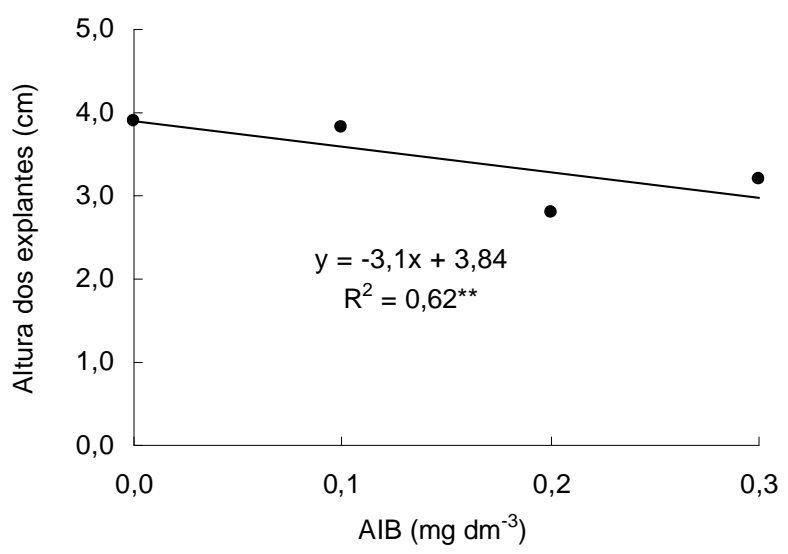

FIGURA 1 - Altura dos explantes coletados no inverno no meio de cultura (Murashige \& Skoog, 1962), em função de concentrações crescentes de ácido indolilbutírico (AIB), aos 30 DAI. ** Significativo pelo teste $F(P<0,01)$

Observando-se a Figura 1, nota-se uma resposta linear decrescente para a altura média dos explantes em função do aumento da concentração de AIB no meio de cultura. Ainda na Figura 1 podese perceber através da altura média alcançada pela testemunha $(3,9 \mathrm{~cm})$ que nos explantes obtidos no inverno a concentração endógena do fitohormônio foi suficiente para auxiliar no desenvolvimento do explante em altura, possivelmente ocasionado pela ação das auxinas no alongamento celular (Taiz \& Zeiger, 2004). Acrescentando-se auxina no meio de cultura houve inibição do alongamento celular, evidenciando que a concentração deste fitoregulador ficou acima do ideal para 0 alongamento do explante.

Os resultados alcançados neste trabalho para a coleta de explantes referente ao o inverno concordam com os resultados alcançados por Zigiotto (2004), onde a concentração de AIB se mostrou indiferente para a altura dos explantes de citronela. Em seu trabalho, a autora ainda relata que ocorreu formação de raízes na testemunha (MS sem fitoreguladores), confirmando os autores Taiz \& Zeiger (2004) que relatam que as auxinas são os únicos fitoreguladores que aumentam a formação de primórdios radiculares, no entanto, algumas espécies formam raízes apenas com o nível endógeno de auxina. Augusto \& Biasi (2002) também obtiveram sucesso no enraizamento in vitro de explantes de amoreira-preta sem a adição de AIB ao meio de cultura.

\section{Número de brotações por explante}

Para esta variável, os fitoreguladores tiveram efeito significativo sobre a multiplicação dos explantes de citronela coletados em todas as estações do ano. Em explantes coletados no outono e no inverno foi observado efeito significativo apenas com a adição de BAP ao meio de cultura. Já em explantes coletados no verão, observaram-se efeitos significativos isolados da adição de AIB e BAP ao meio de cultura. Apenas para os explantes coletados na primavera observou-se interação significativa entre AIB e BAP em relação ao número de brotações por explante.

Para explantes coletados no outono e no inverno, houve efeito significativo da adição de BAP ao meio de cultura, permitindo o estudo de regressão conforme as Figuras $2 \mathrm{a}$ e 2b. Na Figura 2a fica evidente o efeito polinomial quadrático da 
SCHERER-SALVARO, L.M. et al. Época de coleta de explantes...

adição de BAP ao meio de cultura sobre a indução de brotações em explantes de citronela de Java para o outono. Desta forma, confirma-se a importância da citocinina na indução de brotações

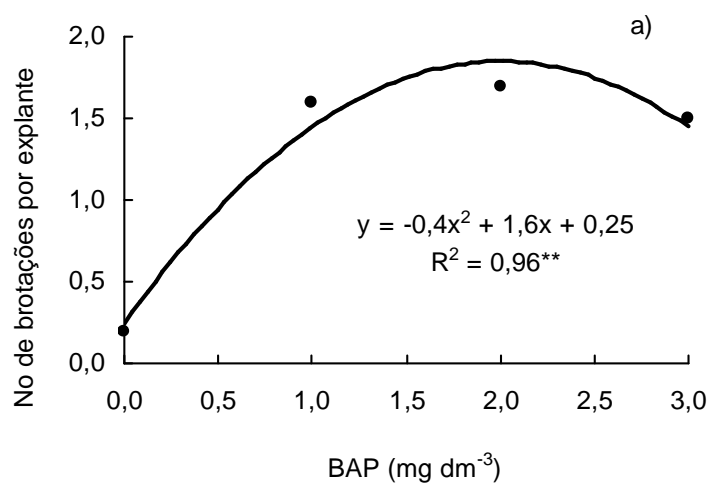

para esta espécie. A concentração ideal de BAP no meio de cultura estimada para esta variável é de $1,99 \mathrm{mg} \mathrm{dm}^{-3}$ resultando em 1,84 brotos por explante de citronela.

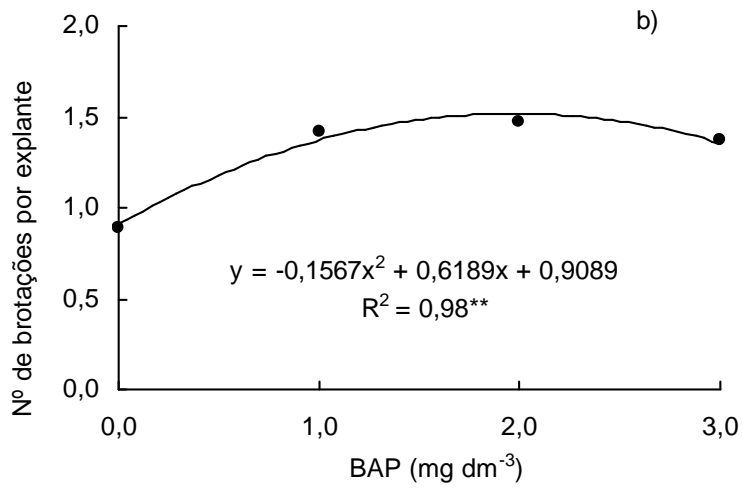

FIGURA 2 - Número de brotações por explante no meio de cultura MS (Murashige \& Skoog, 1962), a) em explantes coletados no outono e b) no inverno, em função de concentrações crescentes de benzilaminopurina (BAP), aos 30 DAI. ** Significativo pelo teste $F(P<0,01)$.

Diniz et al. (2004) com Heliconia stricta Huber, alcançaram resultados significativos com a concentração de $2,0 \mathrm{mg} \mathrm{dm}^{-3}$ de BAP. No entanto, estes verificaram ainda que a concentração de 4,0 $\mathrm{mg} \mathrm{dm}{ }^{-3}$ também não diferiu estatisticamente das concentrações menores testadas. Para casos como este, podem-se utilizar concentrações menores, que proporcionaram resultados numericamente semelhantes às concentrações elevadas, diminuindo custos com o produto utilizado.

Através destes resultados obtidos para a formação de brotos, pode-se supor que o balanço hormonal endógeno não era favorável, pois a testemunha apresentou uma formação de brotos mínima quando comparada aos demais tratamentos.

$\mathrm{Na}$ Figura $2 \mathrm{~b}$, são apresentados os resultados referentes ao número de brotações por explante, obtidos em explantes coletados no

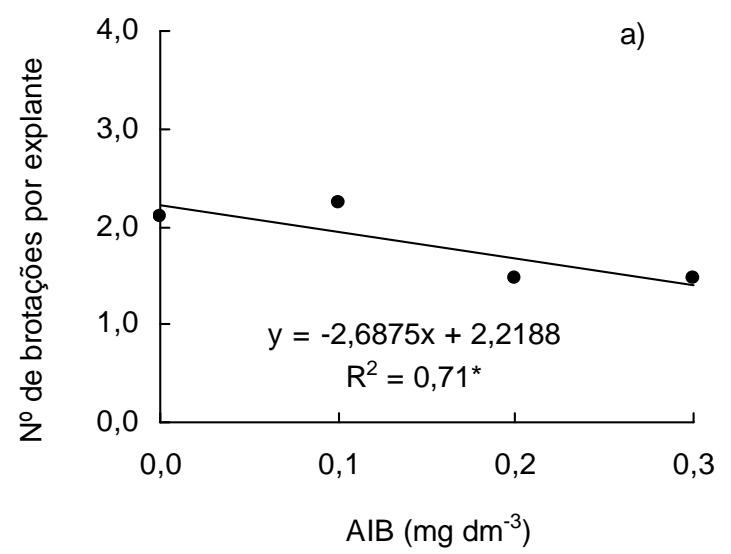

inverno e micropropagados em função da presença de BAP no meio de cultura. Nos resultados obtidos com explantes coletados nesta estação houve um efeito polinomial quadrático para 0 número de brotações por explante em resposta ao BAP. A análise da equação da regressão aponta a concentração de $1,97 \mathrm{mg} \mathrm{dm}^{-3}$ de BAP como sendo a melhor concentração para a multiplicação dos explantes de citronela, resultando em 1,52 brotos por explante. Trabalhando com micropropagação de capim-limão (Cymbopogon citratus), Reis et al. (1999) obtiveram 4,3 brotações por explante utilizando a concentração de $1,0 \mathrm{mg} \mathrm{dm}^{-3}$ de BAP.

As Figuras $3 a$ e $3 b$ referem-se ao número de brotações por explante obtidos em função da época de coleta dos explantes (verão) e das concentrações de AIB e BAP presentes no meio de cultura.

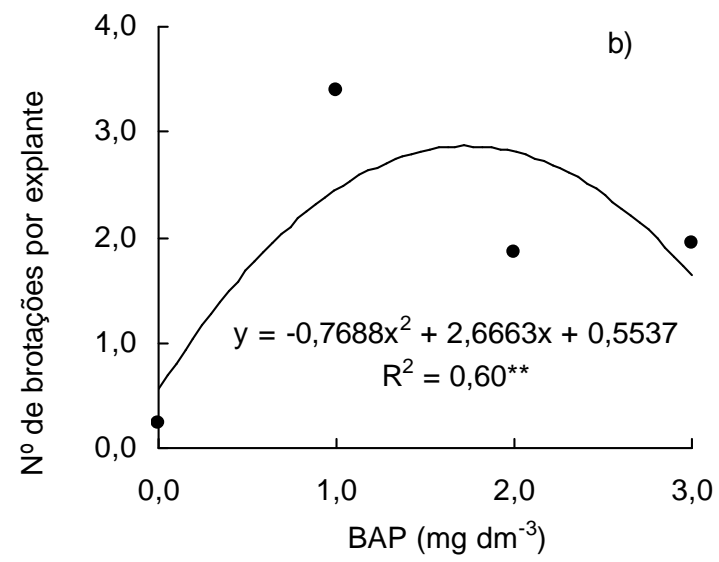

FIGURA 3 - Número de brotações por explante no meio de cultura (Murashige \& Skoog, 1962), em explantes coletados no verão, em função de concentrações crescentes de: a) ácido indolilbutírico (AIB) e b) benzilaminopurina (BAP), aos 30 DAl. * Significativo pelo teste $F(P<0,05)$; ${ }^{* *}$ Significativo pelo teste $F(P<0,01)$. 
Verifica-se na Figura 3a uma resposta linear decrescente do número de brotações por explante em função de concentrações crescentes de AIB acrescentadas ao meio de cultura, enquanto que na Figura $3 \mathrm{~b}$, na mesma estação (verão), para a resposta à adição de BAP ao meio de cultura, houve um comportamento polinomial quadrático para esta variável. Neste caso o máximo de número de brotações por explante foi atingido com a concentração de $1,73 \mathrm{mg} \mathrm{dm}^{-3}$ de BAP, resultando em 2,87 brotos por explante. Estes resultados podem ser explicados pelo próprio efeito fisiológico de ambas as classes de fitoreguladores utilizados neste estudo. Segundo Kerbauy (2008), as auxinas e as citocininas são bastante utilizadas em estudos in vitro, onde o balanço favorável às citocininas induz a emissão de brotações e, balanço favorável às auxinas inibe o desenvolvimento da parte aérea. Além disso, o autor também ressalta que quando aplicadas em concentrações supra-ótimas, as auxinas e citocininas apresentam efeitos inibitórios no crescimento de órgãos vegetais.
Dall'Oglio (2006) também trabalhando com citronela de Java, concluiu que a adição do AIB ao meio de cultura não se justifica para a formação de brotações, pois o mesmo não acrescentou resultados significativos à variável citada. Em estudos de micropropagação com Brachiaria, o meio de cultura foi suplementado somente com citocinina para induzir brotações, e a auxina foi adicionada posteriormente para manutenção da planta in vitro, garantindo o sucesso do protocolo de micropropagação (Cabral et al., 2003).

Já em relação ao BAP, pode-se observar na Figura 3b que sua concentração endógena em explantes coletados no verão não foi suficiente para induzir a formação de brotações, ficando evidente a necessidade de adição deste fitoregulador.

Para os explantes coletados na primavera, pode-se observar através da Tabela 2, que a interação AIB*BAP mostrou-se significativa, demonstrando que ambos os fitoreguladores agiram conjuntamente na indução de brotações.

TABELA 2 - Número de brotações por explante de citronela no meio de cultura (Murashige \& Skoog, 1962), coletados e propagados in vitro na primavera, em função de concentrações crescentes de ácido indolilbutírico (AIB) e benzilaminopurina (BAP), aos 30 DAl.

\begin{tabular}{ccccc}
\hline Concentração de BAP & \multicolumn{4}{c}{ Concentração de AIB no meio de cultura } \\
\cline { 2 - 5 } no meio de cultura & $0,0 \mathrm{mg} \mathrm{dm}^{-3}$ & $0,1 \mathrm{mg} \mathrm{dm}^{-3}$ & $0,2 \mathrm{mg} \mathrm{dm}^{-3}$ & $0,3 \mathrm{mg} \mathrm{dm}^{-3}$ \\
\hline $0,0 \mathrm{mg} \mathrm{dm}^{-3}$ & $0,25 \mathrm{a} \mathrm{A}$ & $0,63 \mathrm{ab} \mathrm{A}$ & $0,63 \mathrm{a} \mathrm{A}$ & 0,38 a A \\
$1,0 \mathrm{mg} \mathrm{dm}^{-3}$ & $0,50 \mathrm{a} \mathrm{A}$ & $0,50 \mathrm{ab} \mathrm{A}$ & $0,50 \mathrm{a} \mathrm{A}$ & 025 a A \\
$2,0 \mathrm{mg} \mathrm{dm}^{-3}$ & $0,87 \mathrm{a} \mathrm{A}$ & $0,25 \mathrm{~b} \mathrm{~A}$ & $0,50 \mathrm{a} \mathrm{A}$ & 0,75 a A \\
$3,0 \mathrm{mg} \mathrm{dm}^{-3}$ & $0,63 \mathrm{a} \mathrm{A}$ & $1,25 \mathrm{a} \mathrm{A}$ & $0,38 \mathrm{a} \mathrm{A}$ & 0,25 a A \\
\hline Média & 0,56 & 0,66 & 0,5 & 0,40 \\
\hline \multicolumn{5}{c}{ CV (\%) } \\
\hline
\end{tabular}

Médias seguidas de mesma letra, minúscula na coluna e maiúscula na linha, não diferem entre si pelo teste de Tukey ao nível de $5 \%$ de probabilidade.

De acordo com a Tabela 2, para os explantes coletados na primavera, a melhor combinação de fitoreguladores é $3,0 \mathrm{mg} \mathrm{dm}^{-3}$ de BAP e $0,1 \mathrm{mg} \mathrm{dm}^{-3}$ de AIB, o que neste trabalho produziu em média 1,25 brotos por explante.

\section{Porcentagem de formação de calo}

Neste estudo, houve formação de calo nos explantes coletados em todas as estações do ano, exceto para os explantes coletados na primavera, onde não houve resultados significativos. Pode-se sugerir que isto ocorreu devido ao balanço endógeno, e mesmo que tenha sido realizada a aplicação exógena de fitoreguladores, tal balanço foi mantido (ZufellatoRibas \& Rodrigues, 2001). O AIB somente influenciou na formação de calo em explantes coletados durante o inverno, já o BAP influenciou na formação de calo em explantes coletados nas estações do outono, inverno e verão.

$\mathrm{Na}$ Figura $4 \mathrm{a}$ verifica-se que houve uma resposta linear crescente à adição de AIB no meio de cultura para a formação de calo. Com a concentração máxima utilizada de $0,3 \mathrm{mg} \mathrm{dm}^{-3}$ obteve-se em média, $65,63 \%$ de explantes que formaram calo, sendo que a testemunha apresentava $46,88 \%$ de explantes com calo. No entanto, mesmo com a formação de calo, o AIB não influenciou na indução de brotação dos explantes, discutida anteriormente. Zigiotto (2004) em seu trabalho com citronela também alcançou resultados semelhantes aos encontrados neste trabalho.

Em relação à influência do BAP em explantes coletados no inverno, nota-se na Figura $4 \mathrm{~b}$, que houve uma resposta polinomial quadrática para a porcentagem de formação de calo em função da adição de BAP ao meio de cultura. A concentração de BAP que resultou em máxima porcentagem de calo foi de $2,0 \mathrm{mg} \mathrm{dm}^{-3}$, resultando em $87,5 \%$ de explantes que formaram calo. Tanto para explantes coletados no verão (Figura 5a) quanto para os explantes coletados no outono (Figura 5b) houve resposta à adição de BAP ao meio de cultura para a formação de calo nos explantes. 
SCHERER-SALVARO, L.M. et al. Época de coleta de explantes...
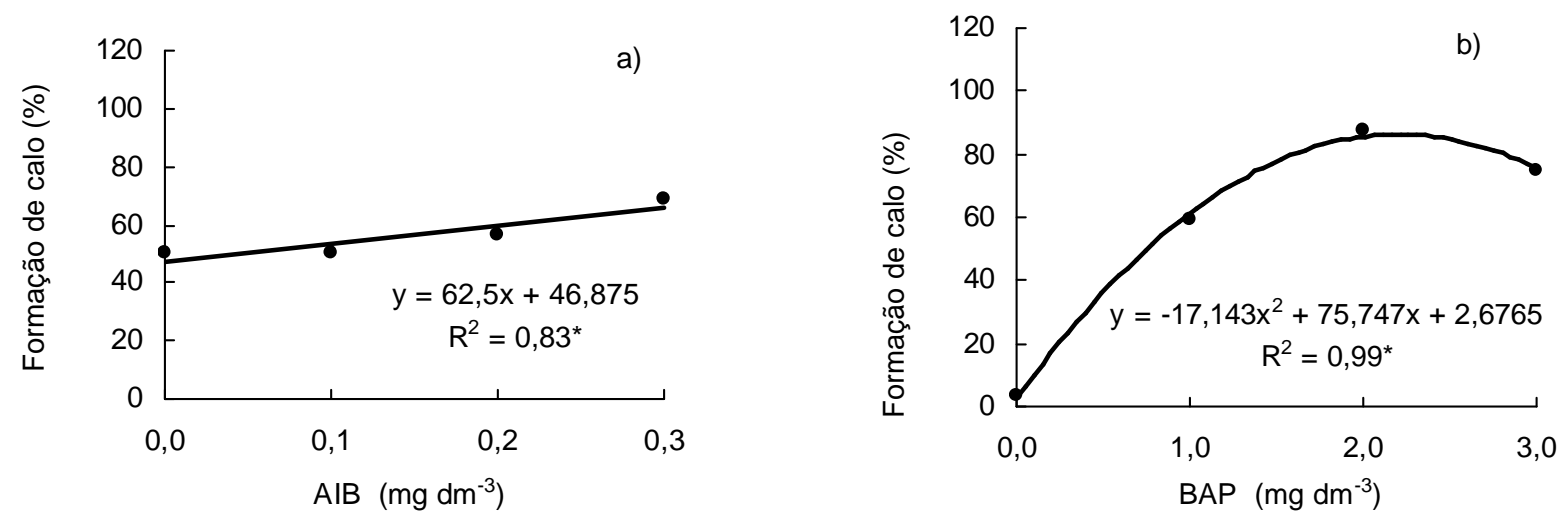

FIGURA 4 - Porcentagem de formação de calo nos explantes em meio de cultura MS (Murashige \& Skoog, 1962), em explantes coletados no inverno, em função de concentrações crescentes de: a) ácido indolilbutírico (AIB) e b) benzilaminopurina (BAP), aos 30 DAI. *Significativo pelo teste $F$ $(\mathrm{P}<0,05) ;{ }^{* *}$ Significativo pelo teste $\mathrm{F}(\mathrm{P}<0,01)$
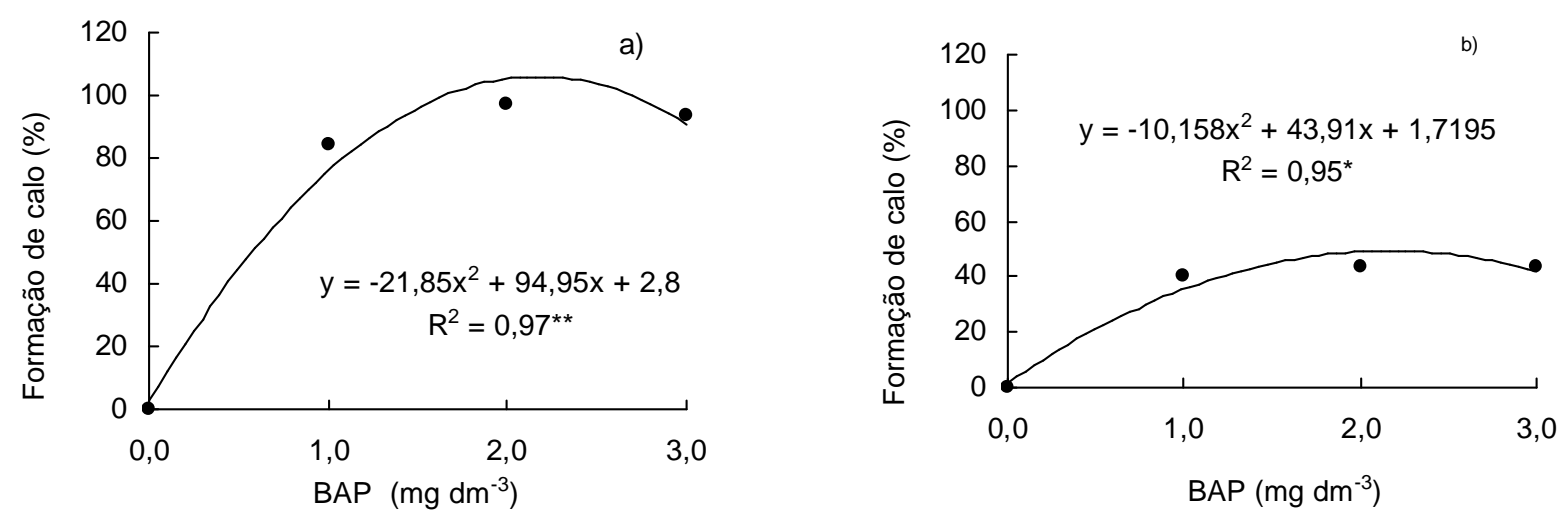

FIGURA 5 - Porcentagem de formação de calo nos explantes em meio de cultura MS (Murashige \& Skoog, 1962), em explantes coletados no verão (a) e no outono (b), em função de concentrações crescentes de benzilaminopurina (BAP), aos 30 DAl. *Significativo pelo teste $\mathrm{F}(\mathrm{P}<0,05)$; ** Significativo pelo teste $F(P<0,01)$

Nas duas estações houve uma resposta polinomial quadrática para esta variável, sendo que no verão a concentração ideal de BAP foi de 2,47 $\mathrm{mg} \mathrm{dm}{ }^{-3}$, resultando na máxima porcentagem de formação de calo, enquanto que no outono a concentração ótima foi de $2,16 \mathrm{mg} \mathrm{dm}^{-3}$ de BAP, também resultando na máxima porcentagem de formação de calo. Na Figura 5a, observa-se relação entre a formação do calo e o número de brotações, pois nos explantes que apresentaram maior porcentagem de formação de calo (explantes coletados no verão, Figura $5 \mathrm{a}$ ) também houve maior formação de brotações por explante (Figura 2b), confirmando o potencial de formação de novas brotações a partir do calo.

Saha \& Ghosh (2003) também propagando citronela in vitro, porém utilizando discos foliares obtiveram formação de calo utilizando $4,0 \mathrm{mg} \mathrm{dm}^{-3}$ de ANA, $0,25 \mathrm{mg} \mathrm{dm}^{-3}$ BAP e $10 \%$ de água de coco. Em seguida os calos foram transferidos para meios de cultura suplementados com concentrações de 0,5 a $2,0 \mathrm{mg} \mathrm{dm}^{-3}$ de BAP e 0,1 a $1,0 \mathrm{mg} \mathrm{dm}^{-3}$ de CIN para a indução de brotações a partir dos calos obtidos. Os autores ressaltam ainda em seu trabalho que este protocolo é simples, rápido e eficaz na propagação desta espécie. Porém, segundo (Grattapaglia \& Machado, 1998) é importante destacar que a formação de calo nem sempre é desejável visto que interfere na fidelidade genética do material propagado.

Vale considerar também que os explantes coletados no verão encontravam-se em condições favoráveis ao seu desenvolvimento, com fotoperíodo, pluviosidade e temperaturas adequadas.

\section{Porcentagem de oxidação}

Para esta variável, somente os explantes coletados no inverno e na primavera apresentaram oxidação, sendo que para os explantes coletados na primavera ocorreu $100 \%$ de oxidação.

Um problema freqüentemente encontrado no cultivo in vitro é o escurecimento dos tecidos lesados do explante causado pela oxidação de compostos fenólicos, o que prejudica o crescimento dos explantes, além de ser um fator de redução da taxa de multiplicação (Utino et al., 2001). 
Abreu \& Mazzafera (2005) trabalhando com Hypericum brasiliense observaram que a concentração de compostos fenólicos aumentou com o déficit hídrico. Em concordância, no inverno/2005 a precipitação foi relativamente baixa, o que pode ter contribuído para a oxidação dos explantes coletados nesta estação. No entanto, existem ainda fatores interno e externos que controlam a produção dos compostos fenólicos, como hormônios, luz e nutrientes.

Observando-se a Figura 6a, pode-se perceber que houve uma resposta polinomial quadrática com a concentração mínima de $0,13 \mathrm{mg}$ $\mathrm{dm}^{-3}$ de AIB, resultando em $81,25 \%$ de oxidação.

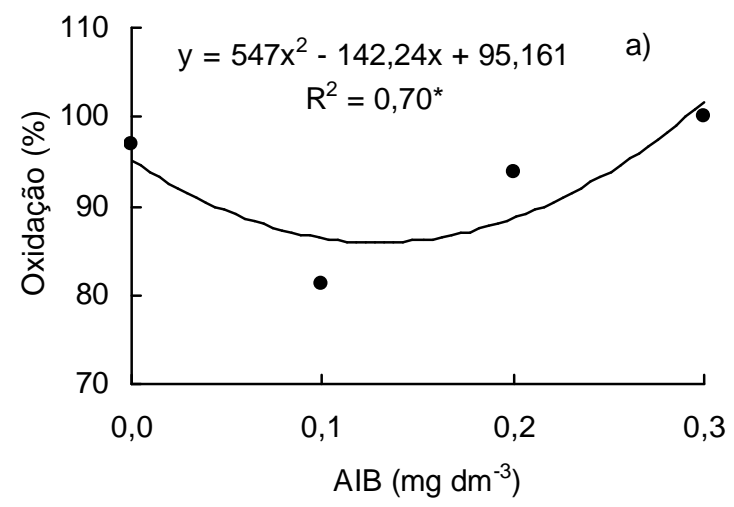

Ao contrário do que aconteceu com o AIB, observase na Figura $6 \mathrm{~b}$ em relação à concentração de BAP, que a testemunha apresentou $100 \%$ de oxidação, enquanto os demais tratamentos apresentaram uma redução na porcentagem de oxidação. A concentração que apresentou menor porcentagem de oxidação foi a de $2,0 \mathrm{mg} \mathrm{dm}^{-3}$ de BAP, com $84,38 \%$ de oxidação. Resultados distintos foram encontrados por Paiva et al. (2004), onde a oxidação do dos explantes de Strelitzia não sofreu interferência com a adição de BAP ao meio de cultura. Já Cai \& Butler (1990) observaram o aumento da oxidação dos explantes de sorgo em meio de cultura devido à adição da citocinina BAP.

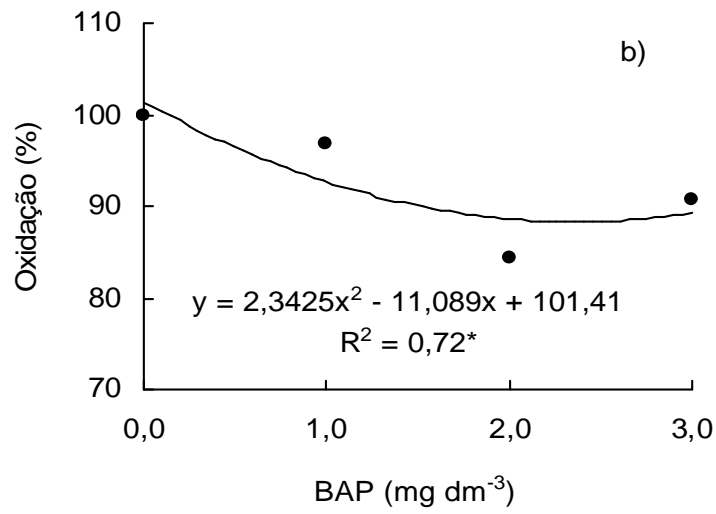

FIGURA 6 - Porcentagem de oxidação nos explantes em meio de cultura MS (Murashige \& Skoog, 1962), em explantes coletados no inverno, em função de concentrações crescentes de: a) ácido indolilbutírico (AIB) e b) benzilaminopurina (BAP), aos $30 \mathrm{DAl}$. *Significativo pelo teste $\mathrm{F}$ $(\mathrm{P}<0,05) ;{ }^{* *}$ Significativo pelo teste $\mathrm{F}(\mathrm{P}<0,01)$

\section{CONCLUSÕES}

De acordo com os resultados obtidos neste trabalho pode-se concluir que para a propagação in vitro da citronela, a melhor estação para coleta dos explantes é o verão, pois, neste estudo proporcionou maior indução de brotações em função da adição de BAP ao meio de cultura e menor porcentagem de explantes oxidados. Nas demais épocas de coleta de explantes o número de brotações por explante foi inferior, não se justificando a coleta de explantes nestas estações.

\section{CONFLITOS DE INTERESSE}

O presente trabalho não apresenta conflitos de interesses que sejam do conhecimento dos autores

\section{REFERÊNCIAS}

1. ABREU, I. N. de; MAZZAFERA, P. Effect of water and temperature stress on the content of active constituents of Hypericum brasiliense Choisy. Plant Physiology and Biochemistry, v. 43, n. 3, p.241-248, 2005.

2. ARAÚJO, R. F.; SIQUEIRA, D. L.; CECON, P. R. Multiplicação in vitro do abacaxizeiro "smooth cayenne" utilizando benzilaminopurina (BAP) e ácido naftalenoacético (ANA). Revista Ceres, v. 55, n. 5, p. 455-460, 2008.

3. AUGUSTO, C. S. S.; BIASI, L. A. Micropropagação da amoreira-preta cv Brazos. Scientia Agraria, v. 3, n. 1-2, p. 113$132,2002$.

4. BLANK, A. F. et al. Influência de número de perfilhos e comprimento da folha no plantio de capim-citronela. In: CONGRESSO BRASILEIRO DE OLERICULTURA, 44., 2004, Campo Grande. Anais... Campo Grande, 2004. p. 1-4.

5. CABRAL, G. B. et al. Introdução in vitro, micropropagação e conservação de plantas de Brachiaria sp. Brasília: EMBRAPA/CENARGEM, 2003. 4 p. (Comunicado Técnico, 101).

6. CAI, T.; BUTLER, L. Plant regeneration from embryogenic callus initiated from immature inflorescences of several hightannin sorghums. Plant Cell, Tissue and Organ Culture, v. 20, n. 2, p. 101-110, 1990.

7. CASTRO, L. O.; CHEMALE, V. M. Plantas medicinais, condimentares e aromáticas: descrição e cultivo. Guaíba: Agropecuária, 1995. $196 \mathrm{p}$.

8. DALL'OGLIO, E. I. Estabelecimento in vitro de citronela de Java (Cymbopogon winterianus Jowitt). $2006.67 \mathrm{f}$ Dissertação (Mestrado em Agronomia) - Universidade Estadual do Oeste do Paraná, Marechal Cândido Rondon, 2006.

9. DINIZ, J. D. N. et al. Avaliação dos efeitos da quebra da dominância apical e do BAP na multiplicação in vitro de Heliconia stricta Huber. Revista Ciência Agronômica, v. 35, p. 232-237, 2004. Número Especial.

10. GRATTAPAGLIA, D.; MACHADO, M. A. Micropropagação. In: TORRES, A. C.; CALDAS, L. S.; BUSO, J. A. (Ed.). Cultura de tecidos e transformação genética de plantas. Brasília: EMBRAPA, 1998. p. 183-260. 
SCHERER-SALVARO, L.M. et al. Época de coleta de explantes...

11. KERBAUY, G. B. Fisiologia vegetal. 2. ed. Rio de Janeiro: Guanabara Koogan, 2008. 452 p.

12. MURASHIGE, T.; SKOOG, F. A revised medium for rapid growth and bio assays with tobacco tissue cultures. Physiologia Plantarum, v. 15, n. 3, p. 473-497, 1962.

13. PAIVA, P. D. de O. et al. Estabelecimento in vitro de estrelícia (Strelitzia reginae Banks.). Ciência e agrotecnologia, v. 28 , n. 5, p. 1031-1037, 2004.

14. REIS, A. F.; LATADO, R. R.; TULMANN NETO, A. Micropropagação de capim-limão (Cymbopogon citratus). In: SIMPÓSIO DE INICIAÇÃO CIENTÍFICA DA USP, 7., 1999, São Paulo. Anais... São Paulo: 1999. 130 p.

15. SAHA, H.; GHOSH, P. D. In vitro plant regeneration of citronella Java (Cymbopogon Winterianus var.Mandakini) using leaf explants and variation in the essential oil content in the regenerants. Journal of Hill Research, v. 16, n. 2, p. 94-98, 2003.

16. TAIZ, L.; ZEIGER, E. Fisiologia vegetal. 3. ed. Porto Alegre: Artmed, 2004. 722 p.

17. UTINO, S.; CARNEIRO, I. F.; CHAVES, L. J. Crescimento e oxidação de explantes de bananeira prata (Musa AAB) in vitro. IV. Concentrações de sais, ácidos ascórbicos e freqüência de subcultivos. Revista Brasileira de Fruticultura, v. 23, n. 2, p. 409-412, 2001.

18. ZIGIOTTO, D. C. Micropropagação de citronela (Cymbopogon winterianus). 2004. 56 f. Monografia (Graduação em Agronomia) - Universidade Estadual do Oeste do Paraná, Marechal Cândido Rondon, 2004.

19. ZUFFELLATO-RIBAS, K. C.; RODRIGUES, J. D. Estaquia: uma abordagem dos principais aspectos fisiológicos. Curitiba: UFPR, 2001. $39 p$

Recebido em 26/09/2008 Aceito em 15/04/2009 